\title{
Pap Uygulamalarının Genç Erkek Futbolcularda Bazı Performans Parametreleri Üzerine Etkisinin İncelenmesi
}

\author{
An Investigation of The Effect of Post-Activation Potentiation on Some \\ Performance Parameters in Young Male Soccer Players
}

\author{
Bülent TURNA * \\ Buğra GENÇTÜRK ** \\ Yücel BULDUK ${ }^{* * *}$
}

\begin{abstract}
Öz: Bu çalışmanın amacı, 6 haftalık PAP uygulamasının genç erkek futbolcularda bazı performans parametreleri üzerine etkisini incelenmektir. Çalışmaya aktif futbol oynayan 26 futbolcu katılmıştır. Futbolcular 13 kişi Klasik Antrenman Grubu (KAG) (yaş 16.84 yıl, sporcu yaş1 4.84 yıl, boy uzunluğu 1.75 m., vücut ağırlığ $63.53 \mathrm{~kg}$., beden kütle indeksi $20.64 \mathrm{~kg} / \mathrm{m}^{2}$ ), 13 kişi ise PAP Uygulama Grubu (PAP) (yaş 17.23yıl, sporcu yaşı 6.23 yıl, boy uzunluğu $1.81 \mathrm{~m}$., vücut ağırlığı $72.07 \mathrm{~kg}$., beden kütle indeksi $21.86 \mathrm{~kg} / \mathrm{m}^{2}$ ) olacak şekilde randomize olarak iki ayrı gruba ayrılmıştır. KAG yalnızca klasik antrenman protokolünü uygularken, diğer gruba ek olarak PAP uygulamaları yaptırılmıştır. Her iki gruba da 6 haftalık uygulama başlamadan önce ve sonra performans testleri uygulanmıştır. KAG grup içi ön ve son testler arasında; T-çeviklik, plankcore, 30 saniye mekik-şınav, durarak çift adım uzun atlama, counter-movement jump, $10 \mathrm{~m}$. ve $20 \mathrm{~m}$. sürat testlerine ilişkin anlamlı farklılıklar bulunmuştur $(\mathrm{p}<0.05)$. PAP grup içi ön ve son testler arasında tüm parametrelerde anlamlı farklılıklar bulunmuştur $(\mathrm{p}<0.05)$. Gruplar arası karşılaştırmada, T-çeviklik, sırt kuvveti, 30 saniye mekik-şınav, durarak çift adım uzun atlama, $10 \mathrm{~m}$. ve $20 \mathrm{~m}$. sürat koşusu, backsquat performanslarına ilişkin ön testlerde KAG lehine farklılıklar varken, son testlerde PAP lehine farklılıklar kaydedilmiştir $(\mathrm{p}<0.05)$. Sonuç olarak futbolcularda, klasik yüklenme yöntemlerine göre PAP uygulamalarının farklı performans değişkenlerini daha fazla geliştirdiği gözlenmiştir.
\end{abstract}

Anahtar sözcükler: Futbol, Fiziksel Performans, PAP

Abstract: The purpose of this study was to investigate the effects of a six-week PAP training program on several performance parameters of male soccer players. A total of 26 young soccer players participated in this study. Participants were randomly assigned into two groups; the Classical Training Group (CTG, n=13) (age=16.84years, experience in sport=4.84years, height=1.75 m., body mass=63.53 kg., BMI=20.64 kg/m²) and the PAP Training Group (PAP, $\mathrm{n}=13$ ) (age=17.23 years, experience in sport=6.23 years, height=1.81 m., body mass=72.07 kg., $\mathrm{BMI}=21.86 \mathrm{~kg} / \mathrm{m}^{2}$ ). While CTG only participated in classical training protocols, PAP conducted both classical and PAP training programs. Both groups were tested at the beginning and end of the six-week programs. In the CTG, statistically significant results were noted in the agility T-test, plank core, 30 second sit-up, push-up, standing long jump, counter-movement jump, $10 \mathrm{~m}$ and $20 \mathrm{~m}$ sprint tests in the group's pre- and post-test results ( $<<0.05)$. In the PAP group, all tests showed statistically significant results from the group's pre- and post-tests $(\mathrm{p}<0.05)$. Comparison between both groups' pre- and post-test t-test results show that pre-test means were in favor of the CTG while the post-test means were in favor of PAP group in the agility, T-test, back strength, 30 second sit-up, push-up, standing long jump, counter-movement jump, $10 \mathrm{~m}$ and $20 \mathrm{~m}$ sprint and back squat tests $(\mathrm{p}<0.05)$. As a result, it was shown that PAP training positively affect some performance parameters.

Keywords: Soccer, Physical Performance, PAP

\footnotetext{
* Dr. Akdeniz Üniversitesi, Sağlık Bilimleri Enstitüsü, Hareket ve Antrenman Ana Bilim Dalı, Antalya, bulentturna@ akdeniz.edu.tr, https://orcid.org/0000-0002-0416-7065

**Akdeniz Üniversitesi, Sağlık Bilimleri Enstitüsü, Hareket ve Antrenman Ana Bilim Dalı, Antalya, bugragencturk@gmail.com, https://orcid.org/0000-0002-1006-8450

***Akdeniz Üniversitesi, Sağlık Bilimleri Enstitüsü, Hareket ve Antrenman Ana Bilim Dalı, Antalya, yucelbulduk@ mynet.com, https://orcid.org/0000-0001-7098-6643
} 


\section{Giriş}

Son yıllarda sporun daha üst düzeyde yapıllyor olması performans beklentilerini arttırmıştır. Bireysel ve takım sporlarında hedeflenen sonuca ulaşmak gittikçe zorlaşmaktadır. Antrenman bilimindeki gelişmeler doğrultusunda antrenörler sporcuların gelişimi için farklı ve yenilikçi antrenman yöntemleri uygulamaktadırlar. Bu çalışmaların ve testlerin sonuçlarına bakılarak uygulanan antrenman yöntemleri değerlendirilmektedir. Tüm bu yenilikçi anlayış doğrultusunda gelişen bilim ve teknoloji ile futbolcuların da performanslarında göze çarpan değişimler ortaya çıkmıştır. Sportif alanda yapılan araştırmalar, performansın yükseltilmesi ve başarının artırılmasına yöneliktir (Turna 2018). Performans sporcunun ortaya çıkardığı verim seviyesi olmakla beraber bazı komponentlerden (fiziksel, fizyolojik, biyomotorik, psikolojik, mental, sosyolojik, teknik, taktik vb.) oluşmaktadır. Performans gelişiminde çok çeşitli antrenman yöntemleri geliştirilmiş ve kombine antrenman modelleri kullanılmaya başlanmıştır (Turna \& Kılınç 2018).

Futbol spor branşının fizyolojik gereklilikleri çok yönlüdür; sporcular yüksek seviyede hız, dayanıklılık, devamlı sprint yeteneği, kas kuvveti ve gücüne sahip olmalıdırlar (Walker \& Turner 2009; Turner et al. 2011; Tufano et al. 2011). Sporcu fitness seviyesi ve antrenman programını optimize edebilmek, sporcu ve takım performansını doğru yönlendirebilmek için gerekli bir durumdur. Özellikle profesyonel futbolda kas gücünü gerekli şekilde optimize edebilmek daha da büyük bir önem taşımaktadır (Wisloff et al. 1998; Eniseler et al. 2005). Fakat sezon içi ve sezon öncesindeki kısa antrenman dönemi, kuvvet ve gücü geliştirmek için gereken antrenman programlarının etkili bir şekilde uygulanmasını kısıtlamaktadır. Bu nedenle kas gelişimini optimize edebilmek adına zamanın verimli kullanılmasını sağlayan antrenman programlarının düzenlenmesi özellikle bu kısımda önem kazanmaktadır. Kompleks (fonksiyonel) antrenman benzer biyomekanik egzersizleri kullanarak hem kuvvet hem de güç kazanımı açısından etkili hem de zamanı verimli kullanan bir antrenman sistemi olarak önerilmektedir (Ebben 2002; Akyüz et al. 2016). Kompleks antrenmanda düşük hız, yüksek yük kullanılan bir egzersizin olduğu antrenmanda yüksek hız, düşük yük içeren bir egzersiz kullanılarak PAP aracılığı ile gücün ortaya çıkışı artırılmaktadır.

Post-activation potentiation (PAP) istemli ve elektriksel olarak uyarılmış kas kasılmaları sayesinde gerçekleşen kuvvet gelişim oranındaki (RFD) artış ile ilişkilendirilebilir (Hanson et al. 2007). Kaslar potensiyelizasyon durumu etkisinde iken görülen RFD artışına, tepe kuvvetine ulaşma süresinde azalmanın katılımı sayesinde sportif aktivitelerde performans artışının potensiyelize edilmiş kaslar tarafından sağlanacağı teorisi öne sürülmektedir. Potensiyelizasyon durumunu kısa veya uzun süreli olabilecek şekilde daha önceden uyarılmış olan sinaps sinyal yollarının sinir iletimlerini daha kuvvetli bir şekilde yapması böylece elektriksel sinir uyarımı iletim hızında ve yoğunluğunda bir artış görülmesi şeklinde açıklayabiliriz.

PAP mekanizmasındaki fizyolojik açıklama net bir şekilde belli olmasa da potensiyalizasyon durumunu dominant bir şekilde açılayan bir teori mevcuttur. Bu teoriye göre PAP sonucunda miyozin düzenleyici hafif zincirlerdeki fosforize olma durumunda bir artı̧s meydana gelmekte, böylece aktin-miyozin döngüsü iyonize kalsiyuma daha hassas hale gelmektedir (Hodgson 2005). PAP, aktin-miyosin etkileşimini geliştiren miyosin düzenleyici hafif zincirlerin fosforilasyonunu içerir. Bu etkileşime gerilmiş kasları hedef almak için kas antagonistinin gönüllü olarak kasılması neden olur (Alp et al. 2018). Maksimal ve maksimale yakın kasılımlar sonucunda artan nöral aktivite düzeyi ile birlikte daha fazla motor ünitenin devreye sokulması ve senkronize edilmesi de PAP'ın neden olduğu fiziksel performans artışı ardındaki sebeplerden biri olduğu düşünülmektedir (Baker 2001).

PAP uygulamasının hem kısa hem de uzun süreli yarar sağladığı düşünülen kompleks (fonksiyonel) antrenman yönteminde pratik olarak kullanıldığı görülebilir (Docherty \& Hodgson 
2007; Matthews et al. 2004; Stone et al. 2008). Kompleks antrenman, spor branşına özgü aktivitenin hayata geçirilmesinden önce benzer kas gruplarına uygulanan farklı spor branş hareketleri içerebilen ve kasa direnç yükleyen bir antrenman modeli olarak düşünülebilir. Maksimal ve maksimale yakın yapilan kas kasılmaları sonucunda kaslar yorgun ve potensiyelize edilmiş konumda kalırlar (Hodgson et al. 2005; Akyüz et al. 2017). Yorgunluk normal hale döndükten bir süre sonra daha potensiyelize edilme durumu korunabilmektedir, işte bu sırada sporcu için "firsat penceresi" denilen bir ergojenik avantaj anı ortaya çıkmaktadır (Hodgson et al. 2005). PAP genel olarak anaerobik ve güce dayalı aktiviteler ile ilişkilendirilmektedir.

PAP durumu sayesinde dikey sıçrama, kısa mesafeli sprint koşusu ve yön değiştirme becerilerinde performans iyileşmesi görüldüğü yapılan çalışmalar sayesinde gözlemlenmiştir (Lima et al. 2011; Tillaar \& Heimburg 2017; Chatzopoulos et al. 2007). Bu performans becerilerinin futbolda sık ihtiyaç duyulan ve kullanılan beceriler oldukları bilinmektedir. Dolayısı ile PAP etkisinin futbol performansında ihtiyaç duyulduğu düşünülen bu parametrelere etkisinin yüksek olması beklenebilir.

Bundan dolayı, bu çalışmada 6 haftalık PAP uygulamasının genç erkek futbolcularda bazı performans parametrelerine etkisinin incelenmesi amaçlanmıştır.

\section{Materyal ve Metot}

$\mathrm{Bu}$ çalışmada Antalya ilinde Devlet Şu İşleri (DSİ) futbol genç erkek takımının lisanslı oyuncuları katılımcı olarak seçilmişlerdir. 26 sporcu çalışmaya dahil edilmiştir. Sporcuların 13 klasik antrenman grubu (KAG), 13 ise PAP antrenman grubu (PAP) olarak randomize bir şekilde gruplandırılmıştır. Sporcuların fiziksel özellikleri Tablo 1 ve Tablo 2'de yer almaktadır.

Tablo 1. Klasik Antrenman Grubundaki Futbolcuların Fiziksel Özellikleri

\begin{tabular}{lllll}
\hline Klasik Antrenman Grubu (n=13) & Minimum & Maksimum & Ortalama & SS \\
\hline Yaş (yl) & 16.00 & 17.00 & 16.84 & 0.37 \\
Spor Yaşı (yıl) & 1.00 & 9.00 & 4.84 & 2.26 \\
Boy (m) & 1.71 & 1.79 & 1.75 & 0.03 \\
Vücut Ağırlığı (kg) & 55.00 & 74.00 & 63.53 & 6.19 \\
Beden Kütle İndeksi $\left(\mathbf{k g} / \mathbf{m}^{2}\right)$ & 18.59 & 23.10 & 20.64 & 1.61 \\
\hline
\end{tabular}

Tablo 2. PAP Uygulama Grubundaki Futbolcuların Fiziksel Özellikleri

\begin{tabular}{lllll}
\hline PAP Uygulama Grubu (n=13) & Minimum & Maksimum & Ortalama & SS \\
\hline Yaş (yıl) & 16.00 & 18.00 & 17.23 & 0.60 \\
Spor Yaşı (yıl) & 1.00 & 9.00 & 6.23 & 2.31 \\
Boy (m) & 1.74 & 1.88 & 1.81 & 0.05 \\
Vücut Ăğırlı̆̆ı (kg) & 59.00 & 81.00 & 72.07 & 6.86 \\
Beden Kütle İndeksi (kg/m $\left.{ }^{2}\right)$ & 18.83 & 23.50 & 21.86 & 1.33 \\
\hline
\end{tabular}

KAG ve PAP gruplarında uygulanan birim antrenman planları Şekil 1'de görülmektedir. 

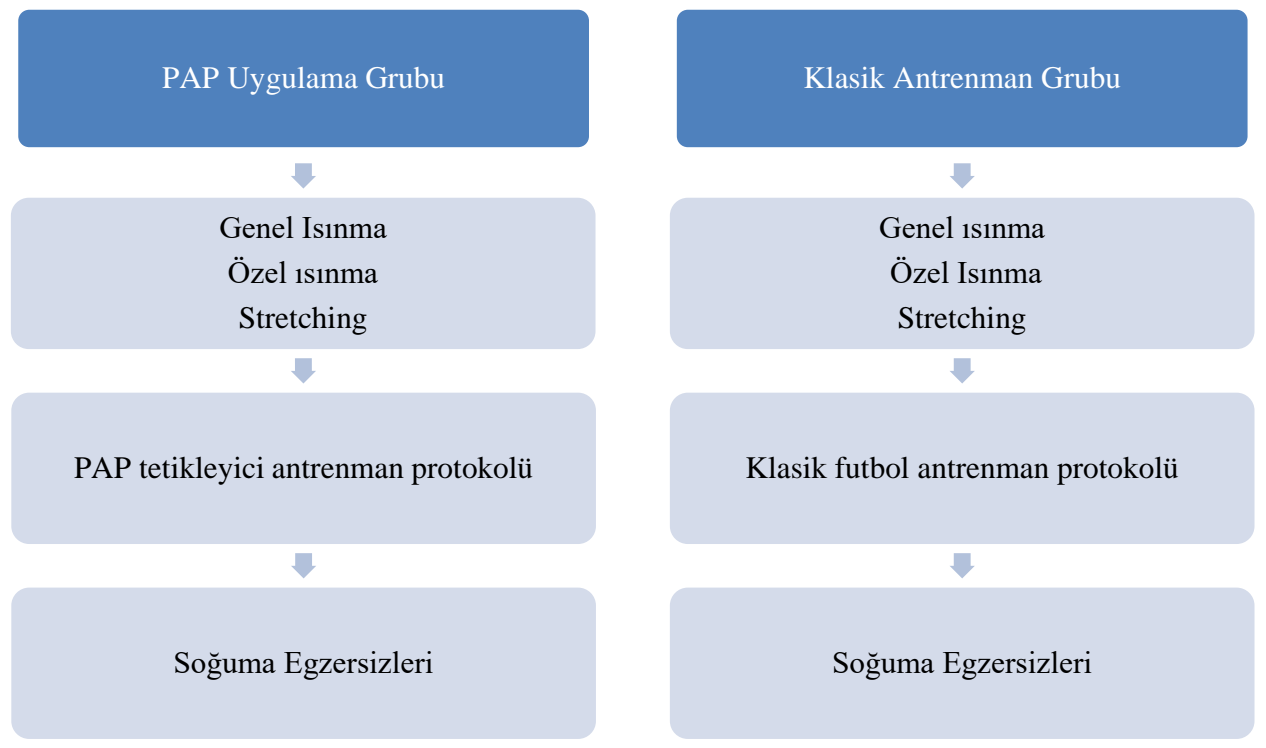

Fig. 1. Her İki Çalışma Grubu İçin de Kullanılan Birim Antrenman Planı

PAP uygulama grubu sporcuları klasik antrenman grubunun uygulamalarına ek olacak şekilde haftada 2 gün (1 salon ve 1 saha antrenmanı), seans başına ortalama 30 dakika ile 45 dakika arasında değişen süreyle PAP tetikleyici antrenman programını toplamda 6 hafta boyunca takip etmişlerdir. Bu araştırma müsabaka dönemi içerisinde yapılmıştır. Dolayısı ile klasik antrenman grubunun 6 haftalık antrenman uygulamalarında rutin koruma antrenmanları ile birlikte, teknik, taktik çalışmalar ve haftada bir gün olmak üzere müsabaka yapılmıştır. Salon ve saha antrenmanlarında uygulanan egzersizler ve set/tekrar sayıları aşağıda Tablo 3 ve Tablo 4'de görülebilir.

Tablo 3. PAP Uygulama Grubu Salon Antrenman Programları

\begin{tabular}{|c|c|c|}
\hline 1. Hafta & 2. Hafta & 3. Hafta \\
\hline $4 \mathrm{x}$ & $4 \mathrm{x}$ & $4 \mathrm{x}$ \\
\hline Power Cleans 15 & Barbell Thrusters 15 & Box Pistol Squat swith Plate Hold 8 (each) \\
\hline Explosive Push Ups 15 & Explosive Bench Presses 12 & Hang Power Cleans 15 \\
\hline $\begin{array}{l}\text { Bench Step Jumps } 12 \\
\text { (each) }\end{array}$ & Burpeesto Bench Jumps Overs 15 & $\begin{array}{c}\text { Alternating Explosive Push Ups on Step } 8 \\
\text { (each) }\end{array}$ \\
\hline Partner Sit Ups 15 & Lat Pull Down with Pause 12 & Partner Leg Raises 21 \\
\hline $\begin{array}{l}\text { Plate Wood choppers } 12 \\
\text { (each) }\end{array}$ & $\begin{array}{l}\text { Plate Jack knifes } 15+\text { Hollow } \\
\text { Body Hold Max. Sec. }\end{array}$ & Knees toVertical Jumps 15 \\
\hline 4. Hafta & 5. Hafta & 6. Hafta \\
\hline $4 \mathrm{x}$ & $4 \mathrm{x}$ & $4 \mathrm{x}$ \\
\hline Pause Back Squats 15 & Explosive Bench Presses 12 & $\begin{array}{c}\text { Plate Reverse Lunge with Bottom Twist to } \\
\text { Single Leg Jumps } 8 \text { (each) }\end{array}$ \\
\hline Hang Muscle Snatches12 & $\begin{array}{l}\text { Plank Leg Raises to Reach Outs } \\
15 \text { (each) }\end{array}$ & Partner Plank Core Challenge 45 sec. \\
\hline $\begin{array}{l}\text { Side to Side Bench } \\
\text { Jumps } 8 \text { (each) }\end{array}$ & Barbell Sumo Squat Jumps 15 & Partner Push Ups to Claps 15 \\
\hline $\begin{array}{l}\text { Plank to Reach Outs } 10 \\
\text { (each) }\end{array}$ & Deficit Explosive Push Ups 15 & $\begin{array}{c}\text { Dumbbell Single Arm Power Snatch to } \\
\text { Overhead Squats } 10 \text { (each) }\end{array}$ \\
\hline $\begin{array}{l}\text { Knees to Squat Stand } \\
\text { Ups } 10 \text { (each) }\end{array}$ & Burpees to Knee Tucks 30 Sec. & Deficit Sumo Dead lifts 15 \\
\hline
\end{tabular}


Tablo 4. PAP Uygulama Grubu Saha Antrenman Programları

\begin{tabular}{|c|c|c|}
\hline 1. Hafta & 2. Hafta & 3. Hafta \\
\hline Partner Resist Band Sprints 20 m. x3 & $\begin{array}{l}\text { Partner Resist Band Backward } \\
\text { Runs } 30 \mathrm{~m} . \text { x3 }\end{array}$ & $\begin{array}{l}\text { Partner Block Backward Runs } \\
20 \mathrm{~m} . \mathrm{x} 3\end{array}$ \\
\hline $\begin{array}{l}\text { Partner Resist Band/ Step to Head Ball } \\
\text { Jumps } 20 \mathrm{~m} \text {. x3 }\end{array}$ & $\begin{array}{l}\text { Partner Resist Band Lateral Slide } \\
\text { Steps } 30 \mathrm{~m} . \text { x3 }\end{array}$ & Partner Block Runs 20 m. x3 \\
\hline $\begin{array}{l}\text { Partner Resist Band Lateral Slide Steps } 20 \\
\text { m. x3 (each side) }\end{array}$ & $\begin{array}{l}\text { Partner Resist Band Diagonal Runs } \\
\qquad 30 \mathrm{~m} . \mathrm{x} 3\end{array}$ & $\begin{array}{l}\text { Partner Block Lateral Runs } 20 \\
\text { m. x3 }\end{array}$ \\
\hline Burpees to Sprints $20 \mathrm{~m} . \mathrm{x} 3$ & Sprint drill $30 \mathrm{~m} . \mathrm{x} 3$ & $\begin{array}{l}\text { Prone Laying to Sprints } 10 \mathrm{~m} . \\
\text { x } 5\end{array}$ \\
\hline 4. Hafta & 5. Hafta & 6. Hafta \\
\hline Single Leg Hops x3 & Plyometric Box Drop Jumps x3 & $\begin{array}{c}\text { Box single leg squats to jumps } \\
10 \text { (each) x2 }\end{array}$ \\
\hline $\begin{array}{l}\text { Partner Resist Band Step to Head Ball } \\
\text { Jumps } 30 \mathrm{~m} \text {. x3 }\end{array}$ & Plyometric Box Squat Jumps x3 & Burpees 15 x2 \\
\hline $\begin{array}{c}\text { Partner Resist Band Step to Lateral Head } \\
\text { Ball Jumps } 30 \mathrm{~m} . \mathrm{x} 3\end{array}$ & $\begin{array}{l}\text { Plyometric Knees to Squat Box } \\
\text { Jumps x3 }\end{array}$ & Box Jumps 20 x2 \\
\hline Lateral Cone Run Drill x3 & $\begin{array}{l}\text { Plyometric Burpees to Box Jumps } \\
\text { x3 }\end{array}$ & Cone Agility Drill x5 \\
\hline Knees to Squat Stand Ups 10 (each) & Shuttle Run Drill x5 & $\begin{array}{c}15 \mathrm{~m} \text {. Sprints (at each } 5 \mathrm{~m} .10 \\
\text { Burpees) x } 3\end{array}$ \\
\hline
\end{tabular}

Futbolcuların 1RM ve bazı performans özelliklerinin ölçümleri altı haftalık antrenman uygulama sürecinden 1 hafta önce ve antrenman sürecinden 1 hafta sonra olacak şekilde ön test ve son test olarak uygulanmıştır. Performans ölçüm testleri aşağıdaki gibidir;

\section{Veri Toplama Araçları ve İşlem Yolu}

\section{T Çeviklik Testi:}

Çeviklik ölçümü için T testi kullanılmıştır. Üç huni aralarında $4.57 \mathrm{~m}$. olacak şekilde aynı hizaya yerleştirilmiştir. Ortadaki B hunisinden $9.14 \mathrm{~m}$. mesafe olacak şekilde A hunisi de yerleştirilmiştir. Uygulayıcılar önce A noktasından B noktasındaki huniye koşarak sağ eliyle huniye dokunması istenmiştir. Daha sonra B hunisinden C hunisine doğru kayma adımlarıyla ulaşarak sol eliyle huniye dokunması istenmiştir. $\mathrm{C}$ hunisinden $\mathrm{D}$ hunisine doğru yana kayma adımlarıyla giderek sağ eliyle dokunup, tekrar yana koşu adımlarıyla B hunisine sol eliyle dokunduktan sonra A noktasına doğru geri geri koşup test tamamlanmıştır. Katılımcıların testi uygulama süreleri kronometreyle ölçülmüştür. Her katılımcı testi iki kez uygulamıştır. 2 denemeden en iyi süre saniye cinsinden kaydedilmiştir (Pauole et al. 2000).

\section{Plank Core Performans Ölçüm Testi:}

Plank core performans ölçümünde Mackenzie (2005) tarafindan geliştirilen protokolden yararlanılmıştır. Testin geçerlilik ve güvenirlilik (\%95. 0.94-0.99) çalışması Tong ve ark. (2013) tarafından yapılmıştır. Bu test sporcuların core kuvvet ve stabilite gelişimini gözlemlemek amacı ile kullanılır. Core Stabilite performans testi180 sn. süreyi kapsamaktadır.

\section{Bacak ve Sirt Kuvveti Testi:}

Bacak ve sirt kuvvetinin belirlenmesinde izometrik bacak ve sirt dinamometresi (Takei BackLift) kullanılmıştır. Bacak kuvvetinde, katılımcılar dizler bükülü durumda $\left(\sim 130^{\circ}\right)$, dinamometre sehpasının üzerine ayaklarını yerleştirdikten sonra kollar gergin, sırt ve gövde düz ve dik 
konumda elleri ile kavradığı dinamometre barını yukarı doğru en yüksek bacak kuvveti ile çekmeleri sağlanmıştır. Bu testte amaç bükülü dizleri bacak kuvveti ile ekstansiyon pozisyonuna getirmektir.

Sırt kuvvetinin değerlendirilmesinde ise, katılımcılar dinamometre sehpasının üzerine ayaklarını yerleştirdikten sonra kollar ve bacaklar düz ve gergin, gövde gergin ancak öne doğru eğilmiş durumda, eller ile kavranan dinamometre barı yukarı doğru en yüksek sirtkuvveti ile çekilmesi sağlanmıştır. Bu testte amaç sırt kuvvetini kullanarak gövdeyi ekstansiyon pozisyonuna getirmektir. Bu ölçümler ikişer defa tekrarlandı ve en iyi değerler kg cinsinden test sonucu olarak kaydedildi.

\section{Saniye Şınav Testi:}

Katılımcılar yere yüz üstü uzanmış pozisyonda, dizler gergin yere temas etmeyecek şekilde vücut ağırlığı ayak uçları ile kollar üzerinde iken vücutlarını kaldırıp indirerek hareket uygulanmıştır. Katılımcının 30 sn. içerisinde tekrar edebildiği şınav sayısı kaydedilmiştir (Pekel 2007).

\section{Saniye Mekik Testi:}

Uygulayıcı dizleri 90 derece bükülü, eller ensede ve ayak tabanları zeminde olacak şekilde sirt üstü pozisyonda başla komutu ile katılımcı gövdesini yukarıya doğru hareket ettirerek başlangıç pozisyonuna geri dönmüştür. Her bir başlangıç pozisyonuna gelişi 1 tekrar olarak değerlendirilmiştir. Test sırasında uygulayıcının ayak bilekleri bir başka katılımcı tarafından tutulmuş ve 30 sn. dolunca test sona erdirilmiş ve skor kaydedilmiştir (Acar 1995).

\section{RM (1 Maksimum Tekrar / 1 RepMax) Testi:}

Geliştirilmiş kuvvet özelliğinin, daha yüksek dikey sıçrama koşular sırasında yer ile temasın azalması ve yön değiştirme gibi futbol için önemli olan performans kriterlerinde önemli ve performans1 etkileyen bir etken olduğu düşünülmektedir (Gabbett et al. 2008; Young et al. 2002; Arampatzis et al. 2001; Akyüz et al. 2016). Bu nedenle üç alt ekstremite ve bir üst ekstremite egzersizi olacak şekilde back squat, bench press,leg extension ve leg curl egzersizleri 1RM protokolleri test sırasında kullanılmıştır. 1RM için gereken yüksek ağırlıkların ölçüm yapılan makinelerde bulunmaması nedeniyle, 1RM ölçümlerinde Haff \& Tripplett'in önerdikleri yöntemle 1RM'nin çoklu tekrarlardan tahmin edilmesi denklemleri kullanılmıştır (Haff \& Tripplett, 2015).

\section{Sürat ve CMJ (Counter Movement Jump) Testi:}

Futbolda sıkça kuvvetli vuruşlar, sprint, top mücadelesi ve dikey sıçrama hareketleri gözlemlenmektedir. Sprint yeteneği ve sıçrama yüksekliği ile mesafesini de içeren güç üretme testlerinin değerlendirilmesinin futbol performansı ile ilişkili olduğu bildirilmektedir (Ronnestad et al. 2008; Little \& Williams 2005; Jullien et al. 2008). Bu nedenle sporcunun hız, güç, kuvvet üretme kapasitesini değerlendirmek antrenörler için sporcunun performansını geliştirmek ve yönlendirmek adına önemlidir. $10 \mathrm{~m}$. ve $20 \mathrm{~m}$. sürat testlerinde Tecnequie marka çift kapılı fotoselle ile ölçülmüştür. Sıçrama yüksekliği Newtest 2000 sıçrama matı üzerinde countermovement jump kullanılarak belirlendi. Üç denemeden en iyi sıçrama kaydedildi. Sıçrama testleri sırasında eller kalçalara yerleştirildi. Denemeler arasında 2 dakikalık bir dinlenme süresi birakıld1 (McMillan et al. 2005).

\section{Çift Adım Uzun Atlama testi:}

Test kaygan olmayan bir zeminde gerçekleştirilmiştir. Katılımcılar başlangıç çizginin gerisinde ve ayakları omuz genişliğinde açık bir pozisyonda beklemişlerdir. Her bir katılımcı hazır olduğunda ellerini geriye doğru çekerken her iki dizini bükerek en uzak mesafeye doğru 
sıçrayarak hareketi gerçekleştirmişlerdir. Başlangıç çizgisi ile katılımıının bıraktığı en yakın iz ölçümü esas alınmıştır. Her uygulayıcıya 2 deneme yaptırılarak en iyi derece kaydedilmiştir (Pekel 2007; Mackenzie 2005; Coşan \& Demir 2005).

\section{Verilerin Analizi}

Tüm değişkenler için aritmetik ortalama ve standart sapma gibi tanımlayıcı istatistik değerler hesaplanmıştır. KAG ve PAP gruplarında farklı ölçüm dönemlerinde (ön-test, son-test) kaydedilen değişkenlerin zaman içerisindeki değişiminin farklı olup olmadığ1 Eşleştirilmiş t Testi ile incelenmiştir. Ayrıca her bir ölçüm dönemine ilişkin KAG ve PAP grupları arasındaki farklılıklar Bağımsız Örneklerde t Testi ile değerlendirilmiş. İstatistik işlemler SPSS paket programında yapılmış ve uygulanan tüm istatistiksel işlemlerde $\alpha=0.05$ hata payı kullanılmıştır.

\section{Bulgular}

Klasik antrenman grubu ön-test son-test karşılaştırması Tablo 5'de, PAP antrenman grubu öntest son-test karşılaştırması ise Tablo 6'da yer almaktadır.

Tablo 5. Klasik Antrenman Grubu Ön-Test Son-Test Karşılaştırması

$* \mathrm{P}<0.05$

\begin{tabular}{|c|c|c|c|c|}
\hline & & Ortalama & $\mathbf{T}$ & $\boldsymbol{P}$ \\
\hline \multirow{2}{*}{ Çeviklik (sn.) } & Ön Test & 10.02 & \multirow{2}{*}{3.14} & \multirow{2}{*}{$0.00 *$} \\
\hline & Son Test & 9.41 & & \\
\hline \multirow{2}{*}{ Plank Core Testi (dk.) } & Ön Test & 1.32 & \multirow{2}{*}{1.48} & \multirow{2}{*}{0.16} \\
\hline & Son Test & 1.35 & & \\
\hline \multirow{2}{*}{ Sirt Kuvvet (kg.) } & Ön Test & 132.50 & \multirow[t]{2}{*}{-1.93} & \multirow[t]{2}{*}{0.07} \\
\hline & Son Test & 139.76 & & \\
\hline \multirow{2}{*}{ Bacak Kuvvet (kg.) } & Ön Test & 123.50 & \multirow[t]{2}{*}{-1.79} & \multirow[t]{2}{*}{0.09} \\
\hline & Son Test & 132.42 & & \\
\hline \multirow{2}{*}{30 Saniye Şınav (tekrar sayısı) } & Ön Test & 29 & \multirow[t]{2}{*}{-2.83} & \multirow[t]{2}{*}{ 0.01* } \\
\hline & Son Test & 31 & & \\
\hline \multirow{2}{*}{30 Saniye Mekik (tekrar sayısı) } & Ön Test & 30 & \multirow[t]{2}{*}{0.85} & \multirow[t]{2}{*}{0.40} \\
\hline & Son Test & 30 & & \\
\hline \multirow{2}{*}{ Durarak Çift Adım Uzun Atlama (m.) } & Ön Test & 2.39 & \multirow[t]{2}{*}{0.35} & \multirow[t]{2}{*}{0.73} \\
\hline & Son Test & 2.38 & & \\
\hline \multirow{2}{*}{ Counter-Movement Jump (cm.) } & Ön Test & 43.92 & \multirow{2}{*}{-2.84} & \multirow{2}{*}{$0.01 *$} \\
\hline & Son Test & 46.07 & & \\
\hline \multirow{2}{*}{10 m. Sprint (sn.) } & Ön Test & 1.69 & \multirow[t]{2}{*}{3.11} & \multirow[t]{2}{*}{$0.00 *$} \\
\hline & Son Test & 1.61 & & \\
\hline \multirow{2}{*}{20 m. Sprint (sn.) } & Ön Test & 3.11 & \multirow{2}{*}{2.77} & \multirow{2}{*}{$0.01 *$} \\
\hline & Son Test & 3.01 & & \\
\hline \multirow{2}{*}{ Bench Press 1RM (kg.) } & Ön Test & 52 & \multirow[t]{2}{*}{-1.97} & 0.07 \\
\hline & Son Test & 56 & & \\
\hline Back Souat 1RM (ko) & Ön Test & 96 & -0.37 & 0.71 \\
\hline Back squat IRIV (kg.) & Son Test & 97 & & \\
\hline Leg Extension 1RM (kg.) & Ön Test & 125 & -0.11 & 0.90 \\
\hline & Son Test & 125 & & \\
\hline Leg Curl 1RM (kg.) & Ön Test & 77 & -0.14 & 0.88 \\
\hline & Son Test & 77 & & \\
\hline
\end{tabular}


Tablo 6. PAP Antrenman Grubu Ön-Test Son-Test Karşılaştırması

\begin{tabular}{|c|c|c|c|c|}
\hline & & Ortalama & $\mathbf{T}$ & $\boldsymbol{P}$ \\
\hline \multirow{2}{*}{ Çeviklik (sn.) } & Ön Test & 10.65 & \multirow{2}{*}{10.05} & \multirow{2}{*}{$0.00 *$} \\
\hline & Son Test & 9.48 & & \\
\hline \multirow{2}{*}{ Plank Core Testi (dk.) } & Ön Test & 1.28 & \multirow{2}{*}{-2.27} & \multirow{2}{*}{$0.04 *$} \\
\hline & Son Test & 1.44 & & \\
\hline \multirow{2}{*}{ Sirt Kuvvet (kg.) } & Ön Test & 124.88 & \multirow{2}{*}{-6.69} & \multirow{2}{*}{$0.00 *$} \\
\hline & Son Test & 141.92 & & \\
\hline \multirow{2}{*}{ Bacak Kuvvet (kg.) } & Ön Test & 111.69 & \multirow{2}{*}{-5.3} & \multirow{2}{*}{$0.00 *$} \\
\hline & Son Test & 126.76 & & \\
\hline \multirow{2}{*}{30 Saniye Şınav (tekrar sayısı) } & Ön Test & 23 & \multirow{2}{*}{-5.06} & \multirow{2}{*}{$0.00^{*}$} \\
\hline & Son Test & 29 & & \\
\hline \multirow{2}{*}{30 Saniye Mekik (tekrar sayısı) } & Ön Test & 27 & \multirow{2}{*}{-7.99} & \multirow{2}{*}{$0.00 *$} \\
\hline & Son Test & 32 & & \\
\hline \multirow{2}{*}{$\begin{array}{l}\text { Durarak Çift Adım Uzun Atlama } \\
\text { (m.) }\end{array}$} & Ön Test & 2.18 & \multirow{2}{*}{-6.44} & \multirow{2}{*}{$0.00 *$} \\
\hline & Son Test & 2.37 & & \\
\hline \multirow{2}{*}{ Counter-Movement Jump (cm.) } & Ön Test & 40.53 & \multirow{2}{*}{-9.81} & \multirow{2}{*}{$0.00 *$} \\
\hline & Son Test & 46.15 & & \\
\hline \multirow{2}{*}{10 m. Sprint (sn.) } & Ön Test & 1.79 & \multirow{2}{*}{8.79} & \multirow{2}{*}{$0.00 *$} \\
\hline & Son Test & 1.60 & & \\
\hline \multirow{2}{*}{20 m. Sprint (sn.) } & Ön Test & 3.22 & \multirow{2}{*}{13.31} & \multirow{2}{*}{$0.00 *$} \\
\hline & Son Test & 2.91 & & \\
\hline \multirow{2}{*}{ Bench Press 1RM (kg.) } & Ön Test & 52 & \multirow{2}{*}{-6.03} & $0.00 *$ \\
\hline & Son Test & 60 & & \\
\hline Back Sauat 1RM (ko ) & Ön Test & 100 & -7.96 & $0.00 *$ \\
\hline 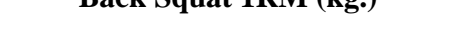 & Son Test & 110 & & \\
\hline Leg Extension 1RM (kg.) & Ön Test & 130 & -5.80 & $0.00 *$ \\
\hline & Son Test & 145 & & \\
\hline Leg Curl 1RM (kg.) & Ön Test & 75 & -4.67 & $0.01 *$ \\
\hline & Son Test & 84 & & \\
\hline
\end{tabular}

$* \mathrm{P}<0.05$

Araştırmamızda KAG ön-test ve son-test sonuçlarının değerlendirilmesinde çeviklik, $30 \mathrm{sn}$. şınav, CMJ, $10 \mathrm{~m}$. ve $20 \mathrm{~m}$. testlerinde istatistiksel olarak anlamlı bir fark bulunmuştur $(\mathrm{p}<0.05)$. PAP uygulama grubunda farklı ölçüm dönemlerinde kaydedilen tüm değişkenlerin zaman içerisindeki değişimlerinde istatistiksel olarak anlamlı bir fark bulunmuştur $(p<0.05)$.

Farklı ölçüm dönemlerinde (ön-test ve son-test) KAG ve PAP gruplarının karşılaştırılmasına ilişkin sonuçlar Tablo 7'de verilmiştir. 
Tablo 7. Farklı ölçüm dönemlerinde (Ön-Test Son-Test) Gruplar Arası Karşılaştırma

\begin{tabular}{|c|c|c|c|c|c|c|}
\hline \multirow{4}{*}{ Çeviklik (sn.) } & & Grup & Ortalama & SS & $T$ & $\mathbf{P}$ \\
\hline & Ön Test & $\frac{\text { KAG }}{\text { PAP }}$ & $\begin{array}{l}10.02 \\
10.65\end{array}$ & $\begin{array}{l}0.81 \\
0.48\end{array}$ & -2.37 & $0.26 *$ \\
\hline & \multirow{2}{*}{ Son Test } & KAG & 9.41 & 0.42 & \multirow{2}{*}{-.51} & \multirow{2}{*}{0.61} \\
\hline & & PAP & 9.48 & 0.27 & & \\
\hline \multirow{4}{*}{ Plank Core Testi (dk.) } & Ön Toct & KAG & 1.32 & 28.00 & \multirow{2}{*}{.30} & \multirow{2}{*}{0.76} \\
\hline & On Test & PAP & 1.28 & 30.36 & & \\
\hline & \multirow{2}{*}{ Son Test } & KAG & 1.35 & 26.13 & \multirow{2}{*}{-1.04} & \multirow{2}{*}{0.30} \\
\hline & & PAP & 1.44 & 10.20 & & \\
\hline \multirow{4}{*}{ Sirt Kuvveti (kg.) } & \multirow{2}{*}{ Ön Test } & KAG & 132 & 16.65 & \multirow[t]{2}{*}{1.12} & \multirow{2}{*}{$0.27 *$} \\
\hline & & PAP & 124 & 17.75 & & \\
\hline & \multirow{2}{*}{ Son Test } & KAG & 139 & 14.95 & \multirow{2}{*}{-.31} & \multirow{2}{*}{0.75} \\
\hline & & PAP & 141 & 19.42 & & \\
\hline \multirow{4}{*}{ Bacak Kuvveti (kg.) } & Ön Toct & KAG & 123 & 20.25 & 186 & 007 \\
\hline & On Test & PAP & 111 & 10.41 & 1.86 & 0.07 \\
\hline & Son Tect & KAG & 132 & 23.84 & 74 & 0.46 \\
\hline & Son Test & PAP & 126 & 13.50 & .14 & 0.40 \\
\hline & Ön Test & KAG & 29 & 4.09 & 2.54 & $0.01 *$ \\
\hline 30 Sanive Sunav (telkrar cavasu) & & PAP & 23 & 6.32 & & \\
\hline 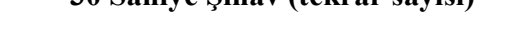 & Son Test & KAG & 31 & 4.26 & 105 & 0.30 \\
\hline & Don lest & PAP & 29 & 6.60 & 1.05 & 0.50 \\
\hline & Ön Test & KAG & 30 & 2.78 & 240 & $002 *$ \\
\hline 30 Sanive Mekik (tekrar savis) & 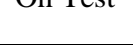 & PAP & 27 & 3.54 & 2.40 & 0.02 \\
\hline 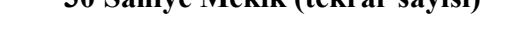 & Son Test & KAG & 30 & 2.77 & -211 & $004 *$ \\
\hline & (5) & PAP & 32 & 3.32 & -2.11 & 0.07 \\
\hline & Ön Test & KAG & 2.39 & 0.15 & 3.82 & $0.00 *$ \\
\hline Durarak Cift Adım Uzun Atlama (m) & & PAP & 2.18 & 0.11 & & 0.00 \\
\hline 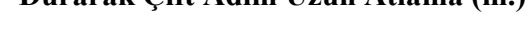 & Son Test & KAG & 2.38 & 0.10 & 0.05 & 0.95 \\
\hline & & PAP & 2.37 & 0.11 & & \\
\hline & Ön Test & KAG & 43.92 & 5.20 & 1.50 & 0.14 \\
\hline Counter-Movement Jumn (cm) & & PAP & 40.53 & 6.23 & & \\
\hline & Son Test & KAG & 46.07 & 4.51 & -0.03 & 0.97 \\
\hline & & PAP & 46.15 & 6.09 & & \\
\hline & Ön Test & KAG & 1.69 & 0.08 & -2.80 & $0.01 *$ \\
\hline $10 \mathrm{~m}$. Sprint (sn.) & & PAP & 1.79 & 0.10 & & \\
\hline & Son Test & KAG & 1.61 & 0.05 & 0.32 & 0.75 \\
\hline & & PAP & 1.60 & 0.06 & & \\
\hline & Ön Test & KAG & 3.11 & 0.14 & -2.26 & $0.03 *$ \\
\hline 20m. Sprint (sn.) & & PAP & 3.22 & 0.08 & -2.20 & $0.03^{3}$ \\
\hline & Son Test & KAG & 3.01 & 0.14 & 1.99 & 0.05 \\
\hline & & PAP & 2.91 & 0.11 & & \\
\hline & Ön Test & KAG & 52 & 5.00 & 0.22 & 0.82 \\
\hline Bench Press 1RM (kg.) & & PAP & 52 & 8.50 & & \\
\hline & Son Test & KAG & 56 & 9.57 & -1.13 & 0.26 \\
\hline & 年 & PAP & 60 & 10.81 & & \\
\hline & Ön Test & KAG & 96 & 7.31 & -0.91 & 0.37 \\
\hline Back Squat 1RM (kg.) & & PAP & 100 & 13.31 & & \\
\hline & Son Test & KAG & 97 & 9.14 & -3.00 & $0.00 *$ \\
\hline & & PAP & 110 & 13.40 & & \\
\hline Leg Extension 1RM (kg.) & Ön Test & KAG & 125 & 17.65 & -0.71 & 0.48 \\
\hline & & PAP & 130 & 18.00 & & \\
\hline
\end{tabular}




\begin{tabular}{|l|c|c|r|r|r|c|}
\hline \multirow{2}{*}{ Leg Curl 1RM (kg.) } & \multirow{2}{*}{ Son Test } & KAG & 125 & 15.92 & \multirow{2}{*}{-2.79} & \multirow{2}{*}{$\mathbf{0 . 0 1}^{*}$} \\
\cline { 3 - 5 } & & PAP & 145 & 18.92 & & \\
\hline \multirow{2}{*}{ Ön Test } & KAG & 77 & 12.19 & \multirow{2}{*}{0.30} & \multirow{2}{*}{0.76} \\
\cline { 3 - 5 } & & PAP & 75 & 13.15 & & \\
\cline { 2 - 5 } & \multirow{2}{*}{ Son Test } & KAG & 77 & 8.98 & -1.90 & \multirow{2}{*}{0.06} \\
\cline { 3 - 4 } & & PAP & 84 & 10.00 & & \\
\hline
\end{tabular}

$* \mathrm{P}<0.05$

Araştırmamızda her bir ölçüm dönemine ilişkin KAG ve PAP grupları arasındaki farklılıklar incelendiğinde gruplar arası ön-testlerin karşılaştırılmasında çeviklik, sırt kuvveti, 30 sn. şınav, $30 \mathrm{sn}$. mekik, durarak çift adım uzun atlama, $10 \mathrm{~m}$. ve $20 \mathrm{~m}$. sürat testlerinde istatistiksel olarak anlamlı bir fark bulunmuştur $(\mathrm{p}<0.05)$. Gruplar arası son-testlerin karşılaştırılmasında ise $30 \mathrm{sn}$. mekik, back squat, leg extension testlerinde istatistiksel olarak anlamlı bir fark bulunmuştur $(p<0.05)$. Genel olarak veriler incelendiğinde ön-testlerde KAG lehine gözlenen farklar 6 haftalık uygulama süreci sonunda PAP uygulama grubu lehine pozitif olarak değişmiştir.

\section{Tartışma ve Sonuç}

Bu çalışmanın amacı 6 haftalık PAP uygulamalarının genç erkek futbolcularda bazı performans parametrelerine etkisinin incelenmesi amaçlanmıştır. Gruplar arası bağımsız $t$ testi sonuçlarında otuz saniye mekik testi, back squat 1RM ve leg extension 1RM son testlerinde PAP antrenman grubunun istatistiksel olarak anlamlı sonuçlar elde ettiği gözlemlenmiştir $(\mathrm{P}<0.05)$. Çalışmanın bulgular kısmında başka bir dikkat edilmesi gereken nokta ise gruplar arası bağımsız t testi sonuçlarında PAP antrenman grubu ile KAG arasında ön testlerde KAG lehine anlamlı bir fark gözlemlenirken son testlerde istatistiksel olarak anlamlı bir fark gözlemlenmese bile bu farkın kapanmış olduğunu söyleyebiliriz. Ön testlerdeki değerlendirilen performans kriterlerinde daha geride olan grup PAP antrenman grubu iken son testlerde bu fark kapanmış ve hatta otuz saniye mekik testi, back squat $1 \mathrm{RM}$ ve leg extension $1 \mathrm{RM}$ gibi performans değerlendirme parametrelerinde PAP lehine istatistiksel olarak anlamlı fark gözlemlenmiştir $(\mathrm{P}<0.05)$.

PAP etkisinin 20 metre sprint performansı üzerine etkisini inceleyen bir çalışmada profesyonel hentbol oyuncuları ile direnç eklenerek koşular uygulanmış ve bu sürecin etkisine bakılmıştır (Tillaar \& Heimburg 2017). Bu çalışmanın sonucunda direnç ile yapılan 20 metre sprint koşularının ardından direnç olmaksızın yapılan sprint koşularında ortalama \%2'lik bir performans artışı gözlemlenmiştir. Futbolda yapılan koşuların ortalama 17 metre olup, yapılan koşuların \%96'lık bir kısmının 30 metreden az olduğu yapılan çalışmalar sonucu gözlemlenmiştir (Bangsbo 1994). Bizim çalışmamızda ise PAP antrenman grubunun 10 ve 20 metre sprint koşularında grup içinde istatistiksel olarak anlamlı bir fark gözlemlenmiş olup $(\mathrm{P}<0.05)$, gruplar arası değerlere bakıldığında ise ön testlerde istatistiksel olarak KAG lehine olan istatistiksel olarak anlamlı farkın son testlerde istatistiksel olarak anlamlı bir fark görülmese bile, PAP antrenman grubu tarafindan yapılan antrenmanlar sonucunda kapatıldığ 1 görülmüştür.

PAP'ın CMJ ve kısa mesafeli sprint üzerine akut etkisini inceleyen bir başka çalışmada ise drop jump egzersizinin CMJ performansina ortalama $\% 6$ ve kısa mesafeli sprint performansina ortalama \%2.4 ve \%2.7 oranlarında olumlu katkıda bulunduğu gözlemlenmiştir (Lima et al. 2011). Direnç egzersizi sonucunda tetiklenen PAP etkisinin dikey sıçramaya olan katkısını incelemeyi amaçlayan bir çalışmada yapılan direnç egzersizinin dikey sıçrama performansına \%2.9 oranında olumlu etkide bulunduğu gözlemlenmiştir (Mitchell \& Sale 2011). Bu akut performans artışının verdiği olumlu etki antrenman programları içerisinde kullanılarak PAP'ın kronik etkisinin gözlemlenmesi çalışmamızda amaçlanmıştır. PAP antrenman grubunun eşleştirilmiş t testi bulgularında $C M J$ ve 10 ve 20 metre sürat performanslarına bakacak olursak ön ve son testler arasında istatistiksel olarak anlamlı bir fark bulunmuştur $(\mathrm{P}<0.05)$. Bağımsız $\mathrm{t}$ testi sonucunda 
ön testlerde CMJ ve 10 ve 20 metre sürat performanslarında KAG lehine istatistiksel olarak anlamlı bir fark varken, son testlerde gruplar arasında istatistiksel olarak anlamlı bir fark gözlemlenmemiştir $(\mathrm{P}<0.05)$. Durarak uzun atlama performans ölçüm testinde PAP antrenman grubu grup içi eşleştirilmiş $\mathrm{t}$ testi bulgularında ön ve son testler arasında istatistiksel olarak anlamlı bir fark bulunmuştur $(\mathrm{P}<0.05)$. Gruplar arası bağımsız $t$ testi sonuçlarında ise ön testlerde KAG lehine istatistiksel olarak anlamlı bir fark gözlemlenirken $(\mathrm{P}<0.05)$, son testlerde istatistiksel olarak anlamlı bir fark bulunamamıştır. Bacak kuvvet testinde PAP antrenman grubu grup içi eşleştirilmiş $t$ testi sonuçlarında ön ve son testler arasında anlamlı fark bulunmuştur $(\mathrm{P}<0.05)$. Bunu PAP antrenman grubunun 6 haftalık antrenman süreci sonundaki performans artışı ile bağdaştırılabilir.

PAP'ın üst beden gücüne olan etkisini incelemek amacı ile yapılan bir çalışmada performans testi öncesi direnç ile yapılan PAP protokolünün üst beden gücünü ortalama güç ve pik güç alanlarında olumlu etkilediği gözlemlenmiştir (Ferreria et al. 2012). Yine PAP protokolünün üst beden kuvvet performans etkisini incelemeyi amaçlayan başka bir çalışmada izometrik kasılmaların PAP etkisi ile birlikte uygulandığındaüst beden kuvvetini olumlu yönde etkilediği gözlemlenmiştir (Esformes et al. 2011). Çalışmamızda, uygulanan 6 haftalık antrenman uygulamalarından sonra yapılan bench press 1RM, 30 saniye şınav testi,plank core stabilite testi ve sırt kuvvet testlerinin sonuçları önceki çalışmaları destekleyici sonuçlar ortaya koymuştur. PAP grubu bench press 1RM, 30 sn. şınav ve mekik testleri, plank core performans ölçüm testi ve sırt kuvvet testlerinde eşleştirilmiş $t$ testleri sonucunda grup içinde ön ve son testler arasında istatistiksel olarak anlamlı bir fark gözlemlenmiştir $(\mathrm{P}<0.05)$. Gruplar arası bağımsız $t$ testi istatistiksel analizinde $30 \mathrm{sn}$. şınav test verilerinde ön testte KAG lehine istatistiksel olarak anlamlı bir fark gözlemlenirken $(\mathrm{P}<0.05)$, son testlerde gruplar arasında istatistiksel olarak anlamlı bir fark gözlemlenmemiştir. Yine bağımsız $t$ testi istatistiksel analizinde otuz saniye mekik test verilerinde ön testlerde KAG lehine istatistiksel olarak anlamlı bir fark gözlemlenirken $(\mathrm{P}<0.05)$, son testlerde istatistiksel olarak anlamlı fark yer değiştirmiş olup PAP antrenman grubu lehine olacak şekilde gözlemlenmiştir $(\mathrm{P}<0.05)$. Gruplar arası bağımsız $\mathrm{t}$ testi sirt kuvvet testi bulgularına göre ön testlerde gruplar arasında KAG lehine istatistiksel olarak anlamlı bir fark gözlemlenirken $(\mathrm{P}<0.05)$, son testlerde gruplar arasında istatistiksel olarak anlamlı bir farka rastlanmamıştır. Bağımsız $\mathrm{t}$ testi analizinde bench press 1RM test verilerinde istatistiksel olarak anlamlı bir fark gözükmese de 6 haftalık antrenman süreci sonunda yapılan son test verileri incelendiğinde PAP antrenman grubunda gözlemlenen 1RM düzeyindeki toplam artış Klasik Antrenman Grubuna göre gelişim gösterdiği görülmüştür. Bu performans artış1 PAP etkisinin sağladığı akut performans artışı sırasındaki ekstra yüklenmelerin sonucunda artan kronik toplam kuvvet ve güç artışı ile bağdaştırılabilir. 10 ve 20 metre sprint koşu testleri, performans ölçümlerinde PAP antrenman grubunun yapılan istatistiksel analiz sonuçlarına bakıldığında ön-testlerde performans açısından geride olmasına rağmen uygulanan PAP uygulamaları sayesinde son testlerde bu anlamlı fark ortadan kalkmıştır.

$\mathrm{Bu}$ araştırmanın sonucunda maç sezonu içerisinde futbolcularda PAP etkisini tetikleyici antrenman uygulamalarının 6 haftalık süreçte (haftada en az iki gün salon ve saha uygulamaları) sporcuların bazı performans parametrelerinde pozitif yönde etki oluşturacağı ortaya konulmuştur. Salon ve saha içi antrenman uygulamalarının ilgili branşın gerekliliklerini de göz önünde bulundurarak uygulanmasına dikkat edilmeli ve PAP etkisinin ortaya çıkarılması maksadıyla yüklenme-dinlenme oranlarına dikkat edilmesi önerilmektedir. 


\section{KAYNAKÇA}

Acar F. (1995). Bayan Futbolcuların Motorik ve Morfolojik Özelliklerinin Performansa Etkileri. Yüksek Lisans Tezi. 1995.

Akyüz M., Uzaldi B. B., Akyüz Ö. \& Doğru Y. (2016). "Comparison of Sprint Reaction and Visual Reaction Times of Athletes in Different Branches". Journal of Education and Training Studies 5(1) (2016) 94-100.

Akyüz M., Agar M., Akyüz Ö. \& Dogru Y. (2016). "Motivational Factors Affecting Athletes in Selecting the Sport Branches of Athletics. Ski and Tennis". Journal of Education and Training Studies 4(12) (2016) 160-165.

Alp M., Çatıkkaş F. \& Kurt C. (2018). "Acute Effects of Staticand Dynamic Stretching Exercises on Lower Extremity Isokinetic Strength in Taekwondo Athletes”. Isokinetics and Exercise Science 26(4) (2018) 307-311

Baker D. (2001). “A Series of Studies on the Training of High-Intensity Muscle Power in Rugby League Football Players”. J Strength Cond Res 15(2) (2001) 198-209.

Bangsbo J. (1994). "The Physiology of Soccer-with Special Reference to Intense Intermittent Exercise”. Acta Physiologica Scandinavica. Supplementum 619 (1994) 1-155.

Behm D. G., Faigenbaum A. D., Falk B. \& Klentrou P. (2008). "Canadian Society for Exercise Physiology Position Paper: Resistance Training in Children and Adolescents". Applied Physiology, Nutrition, and Metabolism 33(3) (2008) 547-561.

Blimkie C. J. "Resistance Training During Pre- and Early Puberty: Efficacy, Trainability, Mechanisms and Persitence". Can J Sport Sci 17 (1992) 264-279.

Coşan F. \& Demir A. (2000). “Türk Çocuklarının Fiziki Uygunluk Normları”. 2000.

Docherty D. \& Hodgson M. J. (2007). "The Application of Post Activation Potentiation to Elite Sport”. International Journal of Sports Physiology and Performance 2(4) (2007) 439-444.

Ebben W. P. (2002). "Complex Training: A Brief Review”. Journal of Sports Science \& Medicine 1(2) (2002) 42.

Esformes J., Keenan M., Moody J. \& Bampouras T. M. (2011). "Effect of Different Types of Conditioning Contraction on Upper Body Post Activation Potentiation”. The Journal of Strength \& Conditioning Research 25(1) (2011) 143-148.

Eniseler N., Çolakoğlu M., Turgay F.,Altun M. \& Vurgun H. (2005). “Türkiye Profesyonel Birinci Ligi Oyuncularında Futbol Hazırlık Dönemi Antrenmanlarının 4mM Laktat Eşiği ve Vücut Yağı Oranı Üzerine Etkisi”. Ege Üniversitesi Performans Dergisi 11(4) (2005) 31-35.

Faigenbaum A. D. (2000). "Strength Training for Children and Adolescents". Clinics in Sports Medicine 19(4) (2000) 593-619.

Ferreria S., Panissa V., Miarka B. \& Franchini E. (2012). "Postactivation Potentiation: Effect of Various Recovery Intervals on Bench Press Power Performance". Journal of Strength and Conditioning Research 26(3) (2012) 739-744.

Akyüz M., Özmaden M., Doğru Y., Karademir E., Aydın Y. \& Hayta Ü. (2017). "Effect of Static and Dynamic Stretching Exercises on Some Physical Parameters in Young Basketball Players”. Journal of Human Sciences 14(2) (2017) 1492-1500.

Haff G. G. \& Triplett N. T. (2015). "Essentials of Strength Training and Conditioning Fourth Edition”. National Strength and Conditioning Association 978-1-4925-0162-6.

Hanson E. D., Leigh S. \& Mynark R. G. (2007). "Acute Effects of Heavy-and Light-Load Squat Exercise on the Kinetic Measures of Vertical Jumping". The Journal of Strength \& Conditioning Research 21(4) (2007) 1012-1017.

Hodgson M., Docherty D. \& Robbins D. (2005). "Post-Activation Potentiation”. Sports Medicine 35(7) (2005) 585-595.

Lima J. B., Marin D., Barquilha G., Da Silva L., Puggina E., Pithon-Curi T. \& Hirabara S. (2011). “Acute Effects of Drop Jump Potentiation Protocol on Sprint and Counter Movement Vertical Jump Performance”. Human Movement 12(4) (2011) 324-330.

Mackenzie B. (2005). “Performans Değerlendirme Testleri”. Londra: Elektrik Dünyast plc

Mayhew J., Kerksick C., Lentz D., Ware J. \& Mayhew D. (2004). "Using Repetitions to Fatigue to Predict One-Repetition Maximum Bench Press in Male High School Athletes”. Pediatric Exercise 
Science 16 (2004) 265-276.

Matthews M. J., Matthews H. P. \& Snook B. (2004). “The Acut Effects of a Resistance Training Warmup on Sprint Performance”. Research in Sports Medicine 12(2) (2004) 151-159.

Mcmillan K., Helgerud J., Macdonald R. \& Hoff J. (2005). "Physiological Adaptations to Soccer Specific Endurance Training in Professional Youth Soccer Players”. British Journal of Sports Medicine 39(5) (2005) 273-277.

Mitchell C. J. \& Sale D. G. (2011). "Enhancement of Jump Performance After a 5-RM Squat is Associated with Post Activation Potentiation". European Journal of Applied Physiology 111(8) (2011) 1957-1963.

Pekel H. A. (2007). "Atletizmde Yetenek Aramasına Bağlı Olarak 10-12 Yaş Grubu Çocuklarda Bazı Değişkenler Üzerinde Normatif Çalışma”. Yayımlanmamış Doktora Tezi. Gazi Üniversitesi, Ankara 2007.

Pauole K., Madole K., Garhammer J., Lacourse M. \& Rozenek R. (2000). "Reliability and Validity of the T-test As a Measure of Agility, Leg Power, and Leg Speed in College-aged Men and Women”. The Journal of Strength \& Conditioning Research 14(4) (2000) 443-450.

Stone M. H., Sands W. A., Pierce K. C., Ramsey M. W. \& Haff G. G. (2008). "Power and Power Potentiation Among Strength-Power Athletes: Preliminary Study”. Int J Sports Phys Perf 3 (2008) 55-67.

Tufano J. J., Amonette W. E., Brown D., Brown L. E., Dupler T. L., Tran T. T. \& Spiering B. A. (2011). "A Novel Equation to Estimate Peak Power in Young Athletes". The Journal of Strength \& Conditioning Research 25 (2011) 31.

Turna B. \& Kılınç F. (2018). "Comparison of Some Biomotoric Properties and Anthropometric Measurements of Male Basketball and Football Players". Journal of Education and Training Studies. Vol. 6. (2018) 118-122.

Turner A., Walker S., Stembridge M., Coneyworth P., Reed G., Birdsey L. \& Moody J. (2011). “A Testing Battery For the Assessment of Fitness in Soccer Players". Strength \& Conditioning Journal 33(5) (2011) 29-39.

Walker S. \& Turner A. (2009). "A One-Dayfield Test Battery For the Assessment of Aerobic Capacity, Anaerobic Capacity, Speed and Agility of Soccer Players”. Strength \& Conditioning Journal, 31(6) (2009) 52-60.

Wisloeff U., Helgerud J. \& Hoff J. (1998). "Strength and Endurance of Elite Soccer Players”. Medicine and Science in Sports and Exercise 30(3) (1998) 462-467.

Gabbett T. J., Kelly J. N. \& Sheppard J. M. (2008). "Speed, Change of Direction Speed and Reactive Agility of Rugby League Players". The Journal of Strength \& Conditioning Research 22(1) (2008) 174-181.

Young W. B., James R. \& Montgomery I. (2002). "Is Muscle Power Related to Running Speed with Changes of Direction?”. Journal of Sports Medicine and Physical Fitness 42(3) (2002) 282-288.

Arampatzis A., Schade F., Walsh M. \& Brüggemann G. P. (2001). "Influence of Leg Stiffness and Its Effect on Myodynamic Jumping Performance”. Journal of Electromyography and Kinesiology 11(5) (2001) 355-364.

Ronnestad B. R., Kvamme N. H., Sunde A. \& Raastad T. (2008). "Short-term Effects of Strength and Plyometric Training on Sprint and Jump Performance in Professional Soccer Players”. The Journal of Strength \& Conditioning Research 22(3), 773-780.

Little T. \& Alun, G. W. (2005). "Specificity of Acceleration. Maximum Speed, and Agility in Professional Soccer Players". Journal of Strength and Conditioning Research 19(1) (2005) 76-78.

Jullien H., Bisch C., Largouët N., Manouvrier C., Carling C. J. \& Amiard V. (2008). "Does a Short Period of Lower Limb Strength Training Improve Performance in Field-Based Tests of Running and Agility in Young Professional Soccer Players?”. The Journal of Strength \& Conditioning Research 22(2) (2008) 404-411. 